\title{
Alkalibacterium indicireducens sp. nov., an obligate alkaliphile that reduces indigo dye
}

\author{
Isao Yumoto, ${ }^{1,2}$ Kikue Hirota, ${ }^{1}$ Yoshinobu Nodasaka, ${ }^{3}$ Yutaka Tokiwa ${ }^{4}$ \\ and Kenji Nakajima ${ }^{4}$
}

Correspondence

Isao Yumoto

i.yumoto@aist.go.jp

\footnotetext{
${ }^{1}$ Research Institute of Genome-based Biofactory, National Institute of Advanced Industrial Science and Technology (AIST), Tsukisamu-Higashi, Toyohira-ku, Sapporo 062-8517, Japan

${ }^{2}$ Graduate School of Agriculture Hokkaido University, Kita-ku, Sapporo 060-8589, Japan

${ }^{3}$ Laboratory of Electron Microscopy, Graduate School of Dentistry, Hokkaido University, Kita-ku, Sapporo 060-8586, Japan

${ }^{4}$ Institute for Biological Resources and Functions, National Institute of Advanced Industrial Science and Technology (AIST), Higashi, Tsukuba, Ibaraki 305-8566, Japan
}

Indigo-reducing, obligately alkaliphilic strains $A 11^{\top}, \mathrm{F} 11$ and $\mathrm{F} 12$ were isolated from indigo fermentation liquor obtained from Tokushima Prefecture, Shikoku, Japan. The isolates grew at $\mathrm{pH}$ 9.0-12.3, but not at $\mathrm{pH}$ 7.0-8.0. The optimum $\mathrm{pH}$ range for growth was 9.5-11.5. They were Gram-negative, facultatively anaerobic, rod-shaped strains with peritrichous flagella. The isolates grew in $0-14 \%(w / v) ~ N a C l$, with optimum growth at $1-11 \%$. They grew at temperatures of $15-35{ }^{\circ} \mathrm{C}$ with optimum growth at around $20-30{ }^{\circ} \mathrm{C}$. DL-Lactate was the major end product from D-glucose. No quinones were detected. The peptidoglycan type was A $4 \alpha$, L-Lys (L-Orn)-D-Asp. The major cellular fatty acids were $\mathrm{C}_{16: 0}, \mathrm{C}_{16: 1} 7 c$ and $\mathrm{C}_{18: 1} 9 c$. The DNA $\mathrm{G}+\mathrm{C}$ contents were 47.0-47.8 mol\%. Phylogenetic analysis based on 16S rRNA gene sequence data indicated that the isolates belong to the genus Alkalibacterium. DNA-DNA hybridization revealed low relatedness values between the isolates and the three phylogenetically most closely related species, Alkalibacterium olivapovliticus, Alkalibacterium psychrotolerans and Alkalibacterium iburiense $(<41 \%)$. On the basis of phenotypic characteristics, including hydrolysis of cellulose and fermentation of carbohydrates, and chemotaxonomic characteristics, phylogenetic data and DNA-DNA relatedness data, it is concluded that the isolates merit classification as representatives of a novel species of the genus Alkalibacterium, for which the name Alkalibacterium indicireducens sp. nov. is proposed. The type strain of this species is $A 11^{\top}$ $\left(=\mathrm{JCM} 14232^{\top}=\right.$ NCIMB $\left.14253^{\top}\right)$.
Since the isolation of the alkaliphilic lactic acid bacterium Alkalibacterium olivapovliticus (Ntougias \& Russell, 2001), six species of alkaliphilic lactic acid bacteria with validly published names have been isolated to date (Ishikawa et al., 2003, 2005; Yumoto et al., 2004; Nakajima et al., 2005; Toffin et al., 2005). They have been isolated from artificial environments such as wash water from edible-olive production and fluid obtained from indigo fermentation, as well as natural environments such as living and decomposing marine organisms. This means that this

Abbreviation: TEM, transmission electron microscopy.

The GenBank/EMBL/DDBJ accession numbers for the 16S rRNA gene sequences of strains $A 11^{\top}, F 11$ and $F 12$ are AB268549-AB268551, respectively.

A supplementary table showing the fatty acid profiles of Alkalibacterium indicireducens sp. nov. and related species is available with the online version of this paper. group of bacteria might be distributed widely in nature and can be isolated by using alkaline media (i.e. $\mathrm{pH} 10$ ). However, the natural habitat of the isolates obtained from artificial environments is not known. This group contains both obligate and facultative alkaliphiles, and the species are facultative anaerobes, do not produce spores and are halotolerant (grow at $>10 \% \mathrm{NaCl}$ ). The range of DNA $\mathrm{G}+\mathrm{C}$ contents is $36.2-43.2 \mathrm{~mol} \%$.

The traditional method of producing indigo blue dye in Japan is based on fermentation by indigenous alkaliphilic bacteria. Harvested indigo leaves are air-dried and then wetted for appropriate bacterial oxidation under careful moisture control. The obtained product is processed further by microbial reduction under alkaline conditions $(\mathrm{pH}>10)$, at which point the original, insoluble, oxidized form of indigo is converted to a soluble, reduced form. If indigo-reducing bacteria can be isolated for use as 
inoculants, it will be easy to initiate proper fermentation. Revival of the traditional method of producing indigo dye would reduce the use of chemical reagents, which are burdens on the natural environment. Indigo-reducing bacteria have been isolated by Takahara \& Tanabe (1960) and Padden et al. (1999) and have been identified as Bacillus sp. and Clostridium isatidis, respectively. However, the bacterium isolated by Takahara \& Tanabe (1960) is unfortunately no longer available. In addition to these isolates, the indigo-reducing bacteria Alkalibacterium psychrotolerans and Alkalibacterium iburiense have also been isolated recently from indigo fermentation liquor obtained from Date City, Iburi, Hokkaido, Japan (Yumoto et al., 2004; Nakajima et al., 2005).

In this study, halotolerant, obligately alkaliphilic lactic acid bacterial strains that can reduce indigo at high $\mathrm{pH}$ were isolated from indigo fermentation liquor samples obtained from Tokushima Prefecture, Shikoku, Japan, and characterized. Results of phenotypic and chemotaxonomic characterization, phylogenetic analysis based on $16 \mathrm{~S}$ rRNA gene sequences, and DNA-DNA hybridization showed that the isolates merit classification as representatives of a novel species of the genus Alkalibacterium, Alkalibacterium indicireducens sp. nov.; the type strain is $\mathrm{A}_{1} 1^{\mathrm{T}}$ (=JCM $14232^{\mathrm{T}}=$ NCIMB $14253^{\mathrm{T}}$ ).

Fermented polygonum indigo (Polygonum tinctorium Lour.) liquor samples were obtained from Tokushima City $\left(34^{\circ} 04^{\prime} \mathrm{N} 134^{\circ} 31^{\prime} \mathrm{E}\right)$ and Aizumi-cho, Itano-gun $\left(34^{\circ} 07^{\prime} \mathrm{N} 134^{\circ} 29^{\prime} \mathrm{E}\right)$, Tokushima Prefecture, Shikoku, Japan, on 30-31 January 2003. Upon reaching the laboratory, $5 \mathrm{ml}$ indigo fermentation liquor was inoculated into $100 \mathrm{ml} 0.01 \%$ indigo-containing PYA (peptone/yeast extract/alkaline) broth consisting of $8 \mathrm{~g}$ peptone (Kyokuto), $3 \mathrm{~g}$ yeast extract (Merck), $1 \mathrm{~g} \mathrm{~K}_{2} \mathrm{HPO}_{4}$, $3.5 \mathrm{mg}$ EDTA, $3 \mathrm{mg} \mathrm{ZnSO} 4.7 \mathrm{H}_{2} \mathrm{O}, 10 \mathrm{mg} \mathrm{FeSO}_{4} \cdot 7 \mathrm{H}_{2} \mathrm{O}$, $2 \mathrm{mg} \mathrm{MnSO}_{4} \cdot 5 \mathrm{H}_{2} \mathrm{O}, 1 \mathrm{mg} \quad \mathrm{CuSO}_{4} \cdot 5 \mathrm{H}_{2} \mathrm{O}, 2 \mathrm{mg}$ $\mathrm{Co}\left(\mathrm{NO}_{3}\right)_{2} \cdot 6 \mathrm{H}_{2} \mathrm{O}$ and $1 \mathrm{mg} \mathrm{H}_{3} \mathrm{BO}_{3}$ in $1 \mathrm{l} \mathrm{NaHCO}_{3} /$ $\mathrm{Na}_{2} \mathrm{CO}_{3}$ buffer $(100 \mathrm{mM}$ in deionized water, $\mathrm{pH} 10)$ at $27{ }^{\circ} \mathrm{C}$. After checking for microbial reduction, the culture was transferred to another $100 \mathrm{ml}$ fresh $0.01 \%$ indigocontaining PYA broth. This enrichment process was carried out five times using the same medium. The enrichment culture thus obtained was inoculated on a reinforced clostridial agar (RCA; Sigma) plate containing $100 \mathrm{mM}$ $\mathrm{NaHCO}_{3} / \mathrm{Na}_{2} \mathrm{CO}_{3}$ buffer pH 10 (alkali RCA) and incubated in an argon-exchanged jar. Three strains that were positive for indigo reduction were identified during the screening process. One strain, $\mathrm{A} 11^{\mathrm{T}}$, was isolated from a sample obtained from Tokushima City, and two strains, F11 and F12, were isolated from a sample obtained from Aizumi-cho, Itano-gun. After $48 \mathrm{~h}$ cultivation, single colonies were selected and re-isolated five times using alkali RCA plates. The purified colonies obtained were inoculated into $0.01 \%$ indigo-containing PYA broth to check the ability of the isolates to reduce indigo. Cells for chemotaxonomic analysis were harvested in the lateexponential phase after cultivation with reciprocal shaking
(130 strokes $\mathrm{min}^{-1}$ ) at $27^{\circ} \mathrm{C}$ in reinforced clostridial broth (RCB) (clostridial nutrient medium; Fluka BioChemika) containing $100 \mathrm{mM} \mathrm{NaHCO} / \mathrm{Na}_{2} \mathrm{CO}_{3}$ buffer, pH 10 (alkali RCB). $\mathrm{NaHCO}_{3} / \mathrm{Na}_{2} \mathrm{CO}_{3}$ buffer for media used in this study was sterilized separately by autoclaving.

For phenotypic characterization, alkali RCA or alkali RCB was used as the basal medium. The culture was incubated at $27{ }^{\circ} \mathrm{C}$ for 2 weeks and experiments were performed three times to confirm the reproducibility of results. Acid production from carbohydrates was determined by the method of Hugh \& Leifson (1953) using thymol blue $(0.008 \%, w / v)$ instead of bromothymol blue at $\mathrm{pH} 10$. Growth experiments at various $\mathrm{pH}$ values were performed using PYA medium containing $100 \mathrm{mM} \quad \mathrm{NaH}_{2} \mathrm{PO}_{4} /$ $\mathrm{Na}_{2} \mathrm{HPO}_{4}$ buffer (pH 7.0-8.0), $100 \mathrm{mM} \quad \mathrm{NaHCO}_{3} /$ $\mathrm{Na}_{2} \mathrm{CO}_{3}$ buffer ( $\mathrm{pH}$ 9.0-10.0), $\mathrm{Na}_{2} \mathrm{HPO}_{4} / \mathrm{NaOH}$ buffer

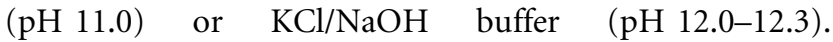
Anaerobic growth was tested in PYA broth $(\mathrm{pH} \mathrm{10)}$ by substituting air with argon. Other physiological and biochemical characteristics were examined according to the methods of Yumoto et al. (1998). Xylan and cellulose hydrolysis was assessed on alkali RCA containing $1 \%$ substrate and judged by the method of Teather \& Wood (1982). Antibiotic sensitivity was investigated by placing a small amount of antibiotic impregnated in a paper disc on plates of alkali RCA medium. For the observation of negatively stained cells by transmission electron microscopy (TEM), cells were grown on alkali RCA. TEM preparation and observation were performed as described previously (Yumoto et al., 2001). The growth rates of the isolates at $\mathrm{pH} 10$ under aerobic conditions in the temperature range $10-40{ }^{\circ} \mathrm{C}$ were determined by using a temperature-gradient incubator (Bio-Photorecorder type $\mathrm{TN}-2612$; Advantec) by monitoring $\mathrm{OD}_{650}$. The isolates can be differentiated from previously reported species belonging to the genus Alkalibacterium by the characteristics listed in Table 1, such as hydrolysis of cellulose and fermentation of carbohydrates.

Bacterial DNA was prepared according to the method of Marmur (1961). DNA base composition was determined by the method of Tamaoka \& Komagata (1984) and the results are shown in Table 1. Analyses of whole-cell fatty acids and isoprenoid quinones were performed as described previously (Yumoto et al., 2002). Peptidoglycan and its hydrolysate were prepared by the method of Okada et al. (1992). Amino acid composition was determined by using a Hitachi L-8500 automated amino acid analyser. GLC analyses revealed that the cellular fatty acid compositions (\%) of strains $\mathrm{A} 11^{\mathrm{T}}, \mathrm{F} 11$ and $\mathrm{F} 12$ are as follows (results are for the type strain and values in parentheses indicate the range found for the three strains): $\mathrm{C}_{10: 0}, 0.7$ $(0.0-0.7) ; \mathrm{C}_{14: 0}, 9.3$ (2.7-9.3); $\mathrm{C}_{14: 1} 5 c, 1.4$ (0.5-1.4); $\mathrm{C}_{14: 1} 7 c, 0.9(0.2-0.9) ; \mathrm{C}_{16: 0}, 42.0(40.0-52.3) ; \mathrm{C}_{16: 1} 5 c$, $2.4(1.7-2.4) ; \mathrm{C}_{16: 1} 7 c, 27.4(15.5-27.4) ; \mathrm{C}_{16: 1} 9 c, 2.7(0.3-$ 2.7); $\mathrm{C}_{18: 0}, 2.3(2.3-8.6) ; \mathrm{C}_{18: 1} 9 t, 0.5(0.5-1.4) ; \mathrm{C}_{18: 1} 9 c$, $11.5(11.5-23.1) ; \mathrm{C}_{20: 0}, 0.3(0.3-5.5)$. Each of the isolates 
Table 1. Differential characteristics of strains $A 11^{\top}, \mathrm{F} 11$ and $\mathrm{F} 12$ and related $A$ lkalibacterium species

Strains: $1, \mathrm{~A}_{1}{ }^{\mathrm{T}}$; 2, F11; 3, F12; 4, A. iburiense strains M3 ${ }^{\mathrm{T}}, 41 \mathrm{~A}$ and 41C; 5, A. psychrotolerans JCM $12281^{\mathrm{T}} ; 6$, A. olivapovliticus NCIMB $13710^{\mathrm{T}}$. + , Positive; -, negative; w, weakly positive; d, strain-dependent. Data for A. iburiense, A. psychrotolerans and A. olivapovliticus are from Nakajima et al. (2005), Yumoto et al. (2004) and Ntougias \& Russell (2001), respectively.

\begin{tabular}{|c|c|c|c|c|c|c|}
\hline Characteristic & 1 & 2 & 3 & 4 & 5 & 6 \\
\hline Gram stain & - & - & - & + & + & + \\
\hline Flagella & Peritrichous & Peritrichous & Peritrichous & Peritrichous & Peritrichous & Polar \\
\hline Optimum pH & $9.5-11.5$ & $9.5-11.5$ & $9.5-11.5$ & $9.5-10.5$ & $9.5-10.5$ & $9.0-10.2$ \\
\hline Temperature range for growth $\left({ }^{\circ} \mathrm{C}\right)$ & $15-40$ & $15-40$ & $18-37$ & $5-45$ & $5-45$ & $4-37$ \\
\hline Optimum temperature $\left({ }^{\circ} \mathrm{C}\right)$ & $20-30$ & $20-30$ & $20-30$ & $30-37$ & 34 & $27-32$ \\
\hline Optimum $\mathrm{NaCl}$ concentration (\%) & $1-11$ & $1-11$ & $1-11$ & $3-13$ & $2-12$ & $0-10$ \\
\hline Specific growth rate, $\mu_{\max }\left(\mathrm{h}^{-1}\right)$ & 0.36 & 0.32 & 0.22 & $0.13-0.26$ & 1.67 & $0.17-0.24$ \\
\hline Hydrolysis of cellulose $\dagger$ & + & + & + & - & - & - \\
\hline \multicolumn{7}{|l|}{ Fermentation of: } \\
\hline D-Arabinose & - & - & - & + & + & - \\
\hline D-Xylose & - & - & - & $\mathrm{d}$ & + & - \\
\hline \multicolumn{7}{|l|}{ Antibiotic sensitivity } \\
\hline Chloramphenicol $(2 \mu \mathrm{g})$ & - & - & - & - & - & + \\
\hline Kanamycin $(2$ and $10 \mu \mathrm{g})$ & - & - & - & - & - & + \\
\hline Trimethoprim (10 and $25 \mu \mathrm{g})$ & - & - & - & - & + & + \\
\hline Peptidoglycan type & $\begin{array}{c}\text { A4 } \alpha, \text { L-Lys } \\
\text { (L-Orn)-D-Asp }\end{array}$ & $\begin{array}{c}\text { A4 } \alpha, \text { L-Lys } \\
\text { (L-Orn)-D-Asp }\end{array}$ & $\begin{array}{c}\text { A4 } \alpha, \text { L-Lys } \\
\text { (L-Orn)-D-Asp }\end{array}$ & $\begin{array}{c}\text { A4 } \alpha, \text { L-Lys-D- } \\
\text { Asp }\end{array}$ & $\begin{array}{c}\text { A4 } \alpha, \text { L-Lys } \\
\text { (L-Orn)-D-Asp }\end{array}$ & $\begin{array}{c}\mathrm{A} 4 \beta, \mathrm{L}-\mathrm{Orn}-\mathrm{D}- \\
\text { Asp }\end{array}$ \\
\hline DNA G $+\mathrm{C}$ content $(\mathrm{mol} \%)$ & 47.1 & 47.0 & 47.8 & $42.6-43.2$ & 40.6 & 39.7 \\
\hline
\end{tabular}

*Upper $\mathrm{pH}$ limit varies depending on strain.

$\dagger$ Hydrolysis of cellulose was tested in this study.

contained a large amount of unsaturated fatty acids. The fatty acid compositions of these three isolates were similar to those of A. iburiense and A. olivapovliticus, rather than to that of A. psychrotolerans (see Supplementary Table S1, available in IJSEM Online). However, the $\mathrm{C}_{16: 0}$ contents of the isolates were higher than those of other Alkalibacterium species. Of members of the genus Alkalibacterium, including the novel isolates, only $A$. psychrotolerans contained a larger amount of $\mathrm{C}_{16: 1} 9 c$ than $\mathrm{C}_{16: 1} 7 c$. Isoprenoid quinones could not be detected by HPLC analysis from the concentrated extracted fraction. The purified peptidoglycans of strains $\mathrm{A} 11^{\mathrm{T}}, \mathrm{F} 11$ and $\mathrm{F} 12$ contained D-Asp, L-Orn + L-Lys, L-Glu and L-Ala in the molar ratio $0.60-0.64: 0.92-1.11: 1: 1.7-2.13$. These results indicated that the strains possess the A $4 \alpha$, L-Lys (L-Orn)-DAsp type of peptidoglycan. The amino acid composition of the peptidoglycan is similar to those of other species belonging to the genus Alkalibacterium [A. psychrotolerans, L-Lys (L-Orn)-D-Asp; A. iburiense, L-Lys-D-Asp].

Fermentation products from D-glucose $[0.5 \%(\mathrm{w} / \mathrm{v})$ in the medium] were analysed by HPLC with TSKgel OApak-A column $(7.8 \mathrm{~mm} \times 30 \mathrm{~cm} \times 2$ columns) (Tosoh). The optical purity of L-lactate in the spent medium was determined by HPLC with a TSKgel ENANTIO L1 column (4.6 $\mathrm{mm} \times 25 \mathrm{~cm} \times 2$ columns) (Tosoh). Lactate, formate and acetate were produced from D-glucose with yields of $1.51-1.75,0.82-1.07$ and $0.14-0.36 \mathrm{~mol}$ (mol glucose $)^{-1}$, respectively. The optical purity of the L-lactate was 46$47 \%$, indicating that the isolate produced DL-lactate.

The 16S rRNA gene was amplified by PCR with primers 9F $\left(5^{\prime}\right.$-GAGTTTGATCCTGGCTCAG-3') and 1541R (5'AAGGAGGTGATCCAGCC-3') for strain A11, 20F (5' AGTTTGATCATGGCTCA-3') and 1541R for strain F11, and $105 \mathrm{~F}$ (5'-GCGGACGGGTGAGTAACAC-3') and 1541R for strain F12. Although the reason is unclear, objective DNA in each strain could be amplified by using the primer sets described above. The PCR product of approximately $1.5 \mathrm{~kb}$ was sequenced directly by the dideoxynucleotide chain-termination method using a DNA sequencer (ABI PRISM 3100) with a BigDye Termination RR mix version 3.1 (Applied Biosystems) according to the manufacturer's instructions. Multiple alignments of the sequences were performed and the nucleotide-substitution rate $\left(K_{\text {nuc }}\right.$ value) was calculated. A 
phylogenetic tree was constructed by the neighbour-joining method (Kimura, 1980; Saitou \& Nei, 1987) using the program CLUSTAL W (Thompson et al., 1994). Similarity values for sequences were calculated using the GENETYX computer program (Software Development). The $16 \mathrm{~S}$ rRNA gene sequences of strains $\mathrm{A} 11^{\mathrm{T}}, \mathrm{F} 11$ and F12 were analysed to determine their phylogenetic positions and compared with those of strains belonging to other phylogenetically related taxa. The phylogenetic tree constructed, including closely related taxa (Fig. 1), showed that the isolates constituted a subcluster with A. olivapovliticus, A. psychrotolerans and A. iburiense and showed high similarities to these Alkalibacterium species. The similarity values among the three isolates were 99.2-99.6\%, whereas those of the isolates to related strains were $<98.6 \%$. The three strains were placed in phylogenetic positions related to A. olivapovliticus (Ntougias \& Russell, 2001), A. psychrotolerans (Yumoto et al., 2004) and A. iburiense (Nakajima et al., 2005), which are all lactate-producing alkaliphiles. The $16 \mathrm{~S}$ rRNA gene sequence of strain $\mathrm{A} 11^{\mathrm{T}}$ had highest similarities to those of the type strains of the obligate alkaliphiles A. olivapovliticus $(98.5 \%)$ and A. psychrotolerans (96.8\%) and to A. iburiense (96.2-96.4\%;

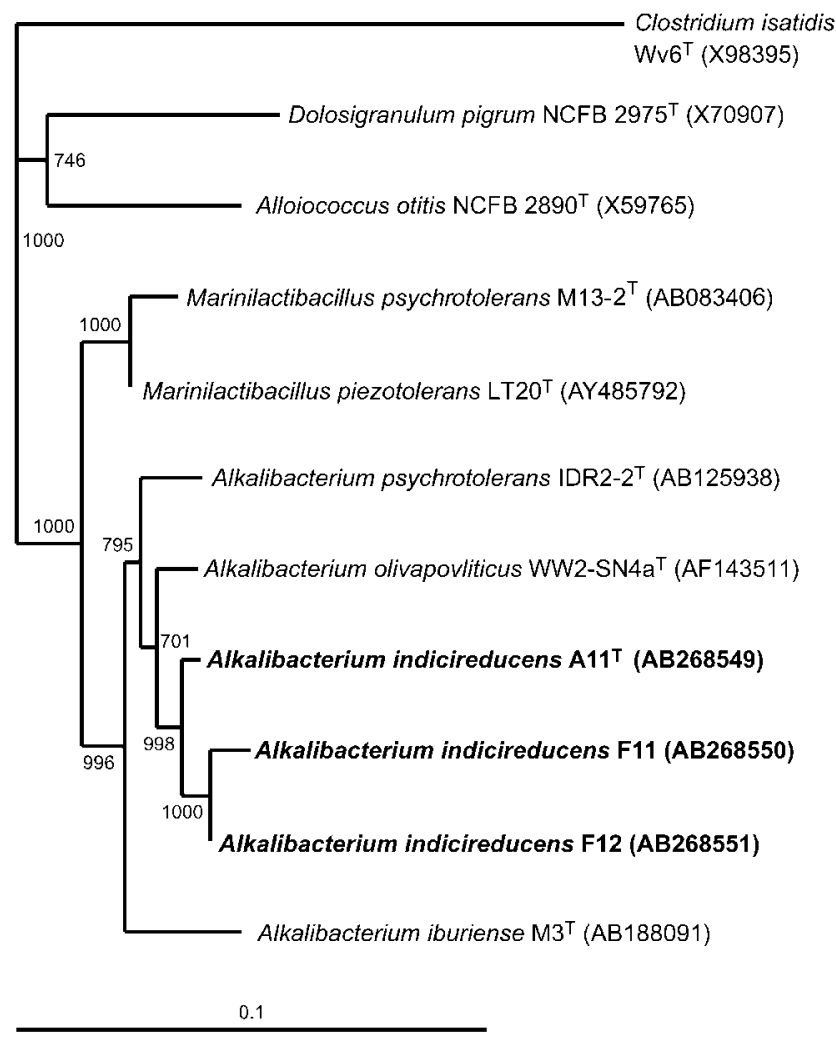

Fig. 1. Phylogenetic tree derived from $16 \mathrm{~S}$ rRNA gene sequence data of $A$. indicireducens strains $\mathrm{A} 11^{\top}, \mathrm{F} 11$ and $\mathrm{F} 12$ and other related organisms by using the neighbour-joining method. Numbers at branching points indicate bootstrap values (from 1000 replicates). Bar, $0.1 K_{\text {nuc }}$. all three known strains, including the type strain), as well as to the sequences of the type strains of the facultative alkaliphile Marinilactibacillus psychrotolerans (95.1\%) and the piezotolerant bacterium Marinilactibacillus piezotolerans $(97.0 \%)$.

On the basis of the results of 16S rRNA gene sequence analysis, A. olivapovliticus NCIMB $13710^{\mathrm{T}}$, A. psychrotolerans JCM $12281^{\mathrm{T}}$ and $A$. iburiense JCM $12662^{\mathrm{T}}$ were used as reference strains for DNA-DNA hybridization. These micro-organisms and the three isolates were cultivated by using the same method. The level of DNA-DNA relatedness was determined fluorometrically by the method of Ezaki et al. (1989) using photobiotin-labelled DNA probes and black microplates. DNA-DNA hybridization results indicated that strains $\mathrm{A} 11^{\mathrm{T}}, \mathrm{F} 11$ and $\mathrm{F} 12$ belong to the same species (87-97\% DNA-DNA relatedness) and that strain $\mathrm{A} 11^{\mathrm{T}}$ differed from A. psychrotolerans JCM $12281^{\mathrm{T}}$ (40\% DNA-DNA relatedness), A. olivapovliticus NCIMB $13710^{\mathrm{T}}$ (21\% DNA-DNA relatedness) and A. iburiense JCM $12662^{\mathrm{T}}$ (34\% DNA-DNA relatedness) when DNA from strain $\mathrm{A} 11^{\mathrm{T}}$ was used as a probe. It is concluded that the three isolates belong to the same species and are different from previously reported Alkalibacterium species.

In addition to the results of the phylogenetic analysis and the DNA-DNA hybridization experiment, strains $\mathrm{A} 11^{\mathrm{T}}$, F11 and F12 differed in terms of growth, phenotypic characteristics and chemotaxonomic characteristics from reported Alkalibacterium species, as shown in Table 1. On the basis of the above results, the isolates represent a novel species of the genus Alkalibacterium, for which the name Alkalibacterium indicireducens sp. nov. is proposed; the type strain is $\mathrm{A} 11^{\mathrm{T}}$.

\section{Description of Alkalibacterium indicireducens sp. nov.}

Alkalibacterium indicireducens (in.di.ci.re.du'cens. L. n. indicum indigo; L. part. adj. reducens bringing or leading back, used to mean 'reducing'; N.L. part. adj. indicireducens indigo-reducing).

Cells are Gram-negative, peritrichously flagellated, straight rods $(0.4-1.2 \times 1.7-3.7 \mu \mathrm{m})$ that do not produce spores. Strains of this species have various degrees of motility; strain F11 exhibits more distinctive motility than strains $\mathrm{A} 11^{\mathrm{T}}$ and F12. Colonies are $0.5-2.0 \mathrm{~mm}$, circular, convex and pale white. Similar-sized colonies are produced during both aerobic and anaerobic growth. Catalase, oxidase and aminopeptidase reactions are negative. DL-Lactate is the major end product from D-glucose. Growth temperature range is $15-40{ }^{\circ} \mathrm{C}$ (strains $\mathrm{Al}^{\mathrm{T}}$ and $\mathrm{F} 11$ ) or $18-37{ }^{\circ} \mathrm{C}$ (strain F12); optimum is $20-30{ }^{\circ} \mathrm{C} . \mathrm{NaCl}$ range for growth is $0-15 \%$ (strain $\mathrm{A} 11^{\mathrm{T}}$ ) or $0-14 \%$ (strains $\mathrm{F} 11$ and $\mathrm{F} 12$ ); optimum is $1-11 \% \mathrm{NaCl}$. Grows at $\mathrm{pH} 9.0-12.3$; optimum growth occurs at $\mathrm{pH}$ 9.5-11.5. Hydrolyses starch, xylan and cellulose, but not casein or gelatin. Ferments D-glucose and sucrose weakly. Fermentation of D-fructose is variable (positive for the type strain). Fermentation of D-arabinose, 
D-xylose, D-galactose, inositol, maltose, raffinose, trehalose, D-mannose, melibiose, L-rhamnose and sorbitol is negative. Growth is not inhibited by chloramphenicol ( 2 and $10 \mu \mathrm{g})$, kanamycin $(2$ and $10 \mu \mathrm{g})$, miconazole $(2 \mu \mathrm{g})$, trimethoprim $(1.25,10$ and $25 \mu \mathrm{g})$, ketoconazole $(25 \mu \mathrm{g})$ or sulfamethoxazole $(25 \mu \mathrm{g})$, but is inhibited by ampicillin (2, 10 and $25 \mu \mathrm{g})$, penicillin $\mathrm{G}(1,2$ and $10 \mathrm{IU})$ and amoxycillin $(10$ and $25 \mu \mathrm{g})$. No quinones can be detected. The major cellular fatty acids are $\mathrm{C}_{16: 0}, \mathrm{C}_{16: 1} 7 c$ and $\mathrm{C}_{18: 1} 9 c$. The peptidoglycan type is A4 $\alpha$, L-Lys (L-Orn)-DAsp. The DNA G + C content is $47.0-47.8 \mathrm{~mol} \%$.

The type strain is $\mathrm{All}^{\mathrm{T}}\left(=\mathrm{JCM} 14232^{\mathrm{T}}=\mathrm{NCIMB} 14253^{\mathrm{T}}\right)$; F11 and F12 are reference strains. All strains were isolated from a polygonum indigo (Polygonum tinctorium Lour.) fermentation liquor. $\mathrm{A}^{\mathrm{T}} \mathrm{T}^{\mathrm{T}}$ was isolated from a sample obtained from Tokushima City and F11 and F12 were isolated from a sample obtained from Aizumi-cho, Itanogun, Japan.

\section{Acknowledgements}

We would like to thank Mr Hirose (Center for Instrumental Analysis, Hokkaido University) for analysing the amino acid composition of peptidoglycan.

\section{References}

Ezaki, T., Hashimoto, Y. \& Yabuuchi, E. (1989). Fluorometric deoxyribonucleic acid-deoxyribonucleic acid hybridization in microdilution wells as an alternative to membrane filter hybridization in which radioisotopes are used to determine genetic relatedness among bacterial strains. Int J Syst Bacteriol 39, 224-229.

Hugh, R. \& Leifson, E. (1953). The taxonomic significance of fermentative versus oxidative metabolism of carbohydrates by various Gram-negative bacteria. J Bacteriol 66, 24-26.

Ishikawa, M., Nakajima, K., Yanagi, M., Yamamoto, Y. \& Yamasato, K. (2003). Marinilactibacillus psychrotolerans gen. nov., sp. nov., a halophilic and alkaliphilic marine lactic acid bacterium isolated from marine organisms in temperate and subtropical areas of Japan. Int J Syst Evol Microbiol 53, 711-720.

Ishikawa, M., Nakajima, K., Itamiya, Y., Furukawa, S., Yamasato, Y. \& Yamasato, K. (2005). Halolactibacillus halophilus gen. nov., sp. nov. and Halolactibacillus miurensis sp. nov., halophilic and alkaliphilic marine lactic acid bacteria constituting a phylogenetic lineage in Bacillus rRNA group 1. Int J Syst Evol Microbiol 55, 2427-2439.

Kimura, M. (1980). A simple method for estimating evolutionary rates of base substitutions through comparative studies of nucleotide sequences. J Mol Evol 16, 111-120.
Marmur, J. (1961). A procedure for the isolation of deoxyribonucleic acid from microorganisms. J Mol Biol 3, 208-218.

Nakajima, K., Hirota, K., Nodasaka, Y. \& Yumoto, I. (2005). Alkalibacterium iburiense sp. nov., an obligate alkaliphile that reduces an indigo dye. Int J Syst Evol Microbiol 55, 1525-1530.

Ntougias, S. \& Russell, N. J. (2001). Alkalibacterium olivoapovliticus gen. nov., sp. nov., a new obligately alkaliphilic bacterium isolated from edible-olive wash waters. Int J Syst Evol Microbiol 51, 1161-1170.

Okada, S., Uchimura, T. \& Kozaki, M. (1992). Nyusankin Jikken Manyuaru (Laboratory Manual for Lactic Acid Bacteria) (in Japanese). Tokyo: Asakura-shoten.

Padden, A. N., Dillon, V. M., Edmonds, J., Collins, M. D., Alvarez, N. \& John, P. (1999). An indigo-reducing moderate thermophile from a woad vat, Clostridium isatidis sp. nov. Int J Syst Bacteriol 49, 1025-1031.

Saitou, N. \& Nei, M. (1987). The neighbor-joining method: a new method for reconstructing phylogenetic trees. Mol Biol Evol 4, 406-425.

Takahara, Y. \& Tanabe, O. (1960). Studies on the reduction of indigo in industrial fermentation vat (VII). J Ferment Technol 38, 329-331.

Tamaoka, J. \& Komagata, K. (1984). Determination of DNA base composition by reversed-phase high-performance liquid chromatography. FEMS Microbiol Lett 25, 125-128.

Teather, R. M. \& Wood, P. J. (1982). Use of Congo red polysaccharide interaction in enumeration and characterization of cellulolytic bacteria from bovine rumen. Appl Environ Microbiol 43, 777-780.

Thompson, J. D., Higgins, D. G. \& Gibson, T. J. (1994). Clustal w: improving the sensitivity of progressive multiple sequence alignment through sequence weighting, position-specific gap penalties and weight matrix choice. Nucleic Acids Res 22, 4673-4680.

Toffin, L., Zink, K., Kato, C., Pignet, P., Bidault, A., Bienvenu, N., Birrien, J.-L. \& Prieur, D. (2005). Marinilactibacillus piezotolerans sp. nov., a novel marine lactic acid bacterium isolated from deep subseafloor sediment of the Nankai Trough. Int J Syst Evol Microbiol 55, 345-351.

Yumoto, I., Yamazaki, K., Sawabe, T., Nakano, K., Kawasaki, K., Ezura, Y. \& Shinano, H. (1998). Bacillus horti sp. nov., a new Gramnegative alkaliphilic bacillus. Int J Syst Bacteriol 48, 565-571.

Yumoto, I., Yamazaki, K., Hishinuma, M., Nodasaka, Y., Suemori, A., Nakajima, K., Inoue, N. \& Kawasaki, K. (2001). Pseudomonas alcaliphila sp. nov., a novel facultatively psychrophilic alkaliphile isolated from seawater. Int J Syst Evol Microbiol 51, 349-355.

Yumoto, I., Nakamura, A., Iwata, H., Kojima, K., Kusumoto, K., Nodasaka, Y. \& Matsuyama, H. (2002). Dietzia psychralcaliphila sp. nov., a novel, facultatively psychrophilic alkaliphile that grows on hydrocarbons. Int J Syst Evol Microbiol 52, 85-90.

Yumoto, I., Hirota, K., Nodasak, Y., Yokota, Y., Hoshino, T. \& Nakajima, K. (2004). Alkalibacterium psychrotolerans sp. nov., a psychrotolerant obligate alkaliphile that reduces an indigo dye. Int $J$ Syst Evol Microbiol 54, 2379-2383. 